\title{
Modelling traffic flow emissions at signalized intersection with PTV vissim
}

\author{
Kudrat Kutlimuratov", Shaukat Khakimov, Akmal Mukhitdinov, and Rustam Samatov \\ Tashkent State Transport University, Tashkent, Uzbekistan
}

\begin{abstract}
The effect of roadway intersection design is strictly linked to a reduction in traffic congestion, fuel consumption and emissions in an urban area. This paper presents a comparative result of the typical four-legged intersection and roundabout operational performance for effective management. Accordingly, a computer model for estimation traffic emissions for two kinds of intersections is created. This study presents a detailed analysis and modelling traffic flow emissions using PTV vissim software and methodology with reasonable solutions to plan a road intersection.
\end{abstract}

\section{Introduction}

Global $\mathrm{CO}_{2}$ emissions are one of the fastest growing sectors in the world in passenger and freight transportation. The share of transport emission is likely to increase carbon dioxide levels again, due to dependence on fossil fuel and the growing demand for mobility and freight transportations.

Environment protection is one of the critical human problems since its solution affects people's lives, health, and welfare. Automobile transport is one of the main polluters of the environment. The harmful gas elements emitted into the atmosphere in the process of the engine operation there are more harmful to human health (carbon dioxide $\left(\mathrm{CO}_{2}\right)$, carbon monoxide $(\mathrm{CO})$, particulate matter $(\mathrm{PM})$, nitrogen oxide $\left(\mathrm{NO}_{\mathrm{x}}\right)$ and volatile organic compounds (VOC)). Large cities, especially in developing countries, are suffering from air pollution of the city. The importance of the problem is more critical in the city, where the density of the automobile is high, which has contributed significantly to the number of traffic emissions.

Traffic flow emission and fuel consumption are strictly linked to a reduction in congestion in an urban area. Traffic congestion corresponds to increases in the frequency of accelerations and decelerations and stop-and-go driving cycles, during which emissions are generated.

There are many pedestrian crossings, traffic signals, and intersections, leading to a higher concentration of emissions in an urban area. It is necessary to consider both traffic congestion and emissions in assessment and optimization for road intersections. In recent years, there are many road intersections; the geometric shape of intersections has been changed several times, which is regulated to reduce traffic congestion. Such changes will

* Corresponding author: qudratq@gmail.com 
require additional construction costs for urban street infrastructure and affect road capacity and its efficiency and urban pollution levels.

Accordingly, it is necessary to identify and systematically estimate traffic emissions for a particular area. In the future, it is important to substantiate issues such as improving traffic efficiency, reducing fuel consumption by optimizing new planned intersections, road network intersections in short-term and long-term development projects.

This paper aims to identify and model traffic emissions with PTV vissim software in the example of Sh.Rustaveli-Shahrisabz -Mirabad intersection.

Often, insufficient research has been done on how traffic emissions can affect the atmosphere when the shape of the intersection changes within a city. Although signalized intersections are widely used, research on exhausted emission from transport in developing countries, including our country, has not been sufficiently studied.

\subsection{Literature review}

In recent years, there has been an increasing number of researchers focusing their research on traffic emission and urban air pollution [1-7].

Several papers [8-12] have been developed to analyze vehicle emissions and evaluate the effects traffic flow on air pollution. For instance, [13] studied GHG and vehicular emissions trends in the China region and [14] proposed a vehicle emission model to study the vehicular emission trend and emission factors and based on vehicle mileage traveled in China. [15-16] adopted emission factors and methodology for calculating exhaust vehicle emissions and data collection approaches.

There are many papers [17-19] and where emissions from transport have been accounted for through modelling approaches. At the local scale, traffic network models can provide planners with information about the emission impacts of infrastructure decisions by predicting traffic flows. Some scientific papers [20-24] are reviewed and discussed using vehicle emissions monitoring methods and focused on measuring and analysing world vehicle emissions.

This [25] study examines the impact of factors such as bus travel time and delay, number of stops on routes, and spent times, and aims to find solutions to minimize delays. The effect of scheduled and unscheduled stops was studied using a linear multivariate regression model and developed based on the collected data.

Many studies showed that implementing ITS applications such as advanced traffic management systems, advanced traveler information systems, and advanced vehicle control systems is one of the potential effects of minimising negative traffic impacts, including traffic congestion, and reducing fuel consumption and traffic emissions [26-27]. Several mathematical and simulation-based methods have been developed to optimize signal times at regulated intersections.

There are many factors influencing traffic emissions. They are traffic density, road capacity, automobile operating conditions and technical specifications and external environmental conditions. Exhausted emissions from traffic on urban streets depend primarily on intersection and traffic signals' geometric and efficiency characteristics.

Using transport technology measures, shifting new type of fuels in the powertrain system, technological improvements and optimal engine operation conditions, criteria pollutant emissions per unit of length traveled have been significantly reduced.

A few studies from the reviewed literature have focused on modeling traffic emissions at signalized intersections. 


\section{Methods}

\subsection{Case study and Data collection}

We know that traffic flow emissions at an intersection have serious negative effects on the environment and human health. So, we want a more in-depth understanding of the impact of traffic exhaust emissions on the local scale.

The first step for traffic emission analysis is a choice intersection and data collection to calculate traffic emissions. These data include traffic volume, vehicle category and type, intersection characteristics and users (pedestrians and bicyclists).

We have chosen one of the intersections for the research purpose of the study. The existing intersection layout design from Google map is shown in Figure 1. And we want to comparative analysis point of views the on environmental effect of intersection shape. In Tashkent, the shape of the intersection of Shota Rustaveli-Shahrisabz-Mirabad streets was changed from a typical channelized intersection type (+) to roundabout (o) in 2the 011 . In case of our study four-legged intersection is consist of two main crossing roads. Shota Rustaveli and Shakhrisabz streets are 4+4 lanes, Mirabad streets are 3+3 lanes, and the circular island in the central part of the intersection diameter is $42 \mathrm{~m}$. The maximum speed of vehicles on the roads of the city is set at $70 \mathrm{~km} / \mathrm{h}$.

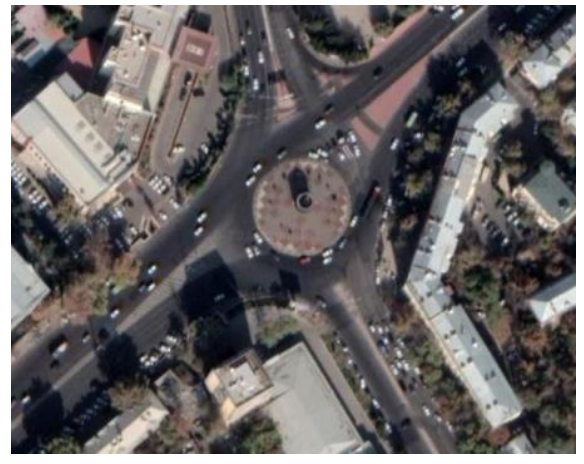

a) Existing intersection in 2020

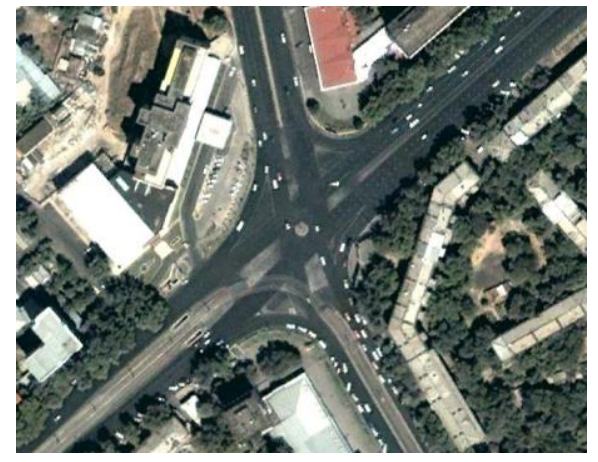

b) Existing intersection in 2010

Fig. 1. Existing intersection layout plan (Google map)

The geometric characteristics of the existing roads of the intersection, road signs, length of congestion, as well as data on the number of road traffic accidents were analyzed.

Traffic is usually analyzed on average weekly days, months. Rapid traffic analysis can also be performed at intervals of hours of the day.

A daily (12-hour) traffic flow was conducted and collected during a normal working day. Vehicle category and composition was observed from a video camera; it was installed at the intersection, traffic volume during the morning and afternoon rush hours is shown in Figure 2. Traffic volume on the street during the observation ranged from 1,900 to 5,600 per hour. The average daily traffic is more than 55,000 cars. In addition, vehicle delays, queue lengths, and other important factors were analyzed. All the necessary information about each vehicle, the number of vehicles moving in different directions, including cars, trucks, buses, were included in the program database performed using PTV vissim and used to calculate traffic emissions.

In the model, the intensity of motor traffic and pedestrian flow, as well as the data distributed along the routes of traffic flows, were loaded into the program at one-hour daily values (Figures 3 and 4) by analytical counting and calculations were performed. 
Nowadays, the total number of vehicles is growing rapidly relative to the population in Uzbekistan, accordingly demands for transport services is growing. More than 3.5 million vehicles are registered in our country, and an increase in the number of these vehicles is an average of $5-7 \%$ per year. In particular, in Tashkent, more than $0.5 \mathrm{mln}$. vehicles are registered, and an average of several hundred vehicles entered and left the city per day.

The linear increment (cumulative) method was used to forecast the traffic projection. Traffic flow forecasts for 2025 at an average annual growth rate of 5\% are given in Table 1 .

Table 1. Traffic projection

\begin{tabular}{|c|c|c|c|}
\hline Year & $\begin{array}{c}\text { Daily traffic } \\
\text { volume }\end{array}$ & $\begin{array}{c}\text { Growth rate compared to } \\
2020\end{array}$ & $\begin{array}{c}\text { Hourly traffic } \\
\text { volume }\end{array}$ \\
\hline 2020 & $>55000$ & 1 & 5500 \\
\hline 2025 & $>70000$ & 1.4 & 7700 \\
\hline
\end{tabular}

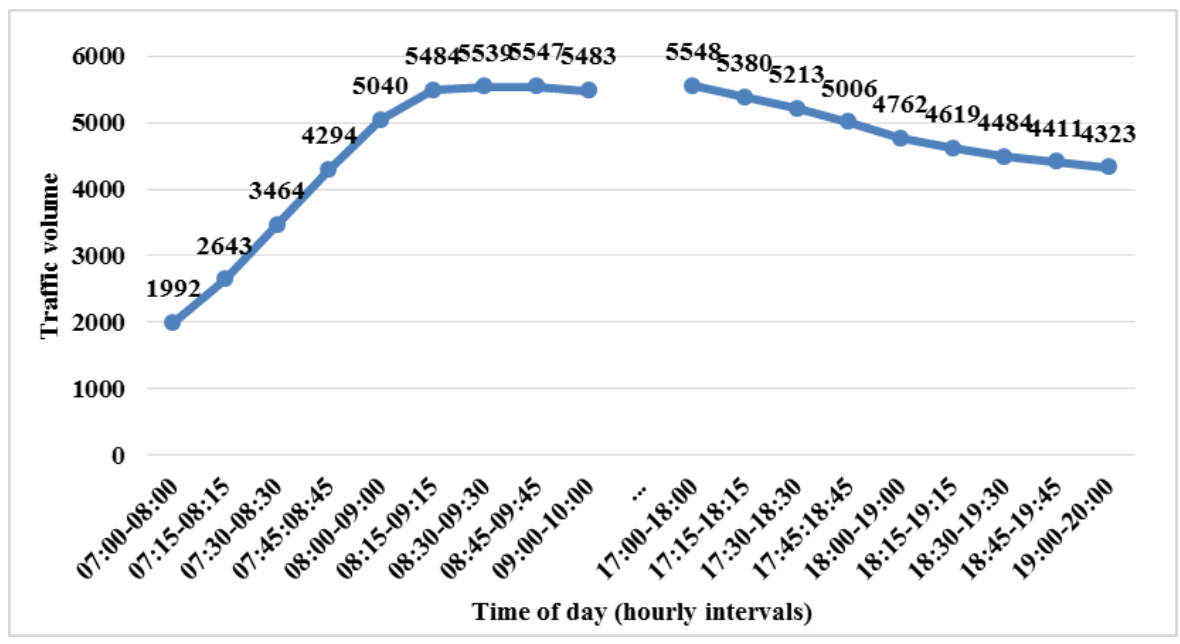

Fig.2. Variation of hourly traffic volume at the intersection
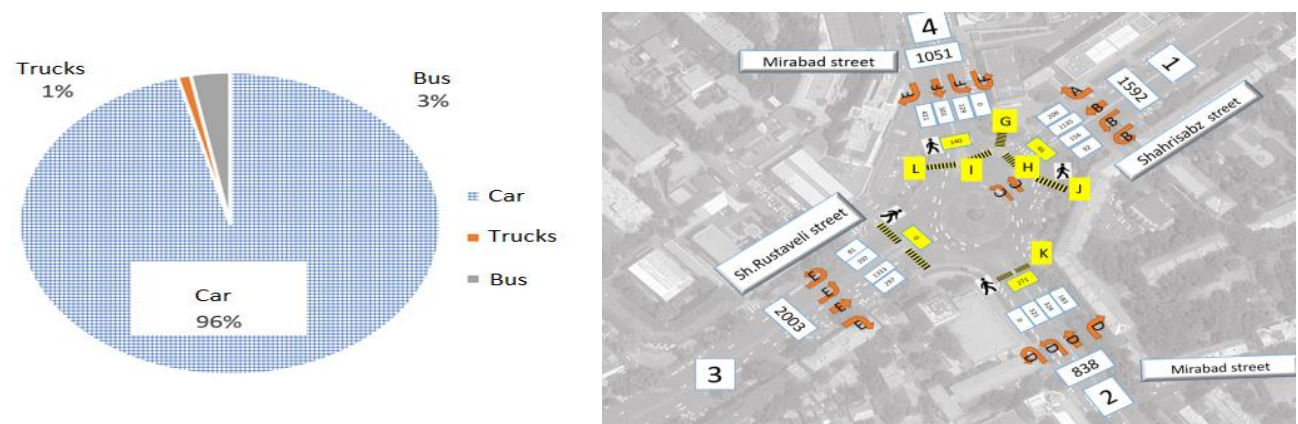

Fig.3. Vehicle composition

Fig.4. Traffic volume for AM peak hour

\subsection{Emission Model}

The EU emission standard is the most commonly used in the world. According to the EU standards, which were adopted for new gasoline-fueled cars and provided the definition of a standard. 
Generally, estimation of traffic emissions can be based on the following equation:

$$
\text { Emission }=E_{f} \cdot d
$$

Where, Emission is the amount of emission (CO, NOx, VOC), $E_{f}$ is relative emission factor per unit of activity, and $d$ is the travel distance and (1) equation has to be used for each category of vehicle and number of transport activity.

Research paper [28] indicates that fuel consumption and $\mathrm{CO}_{2}$ levels per kilometer traveled is not linear. There is a high fuel consumption rate and $\mathrm{CO}_{2}$ emission if the vehicle speed is below $50 \mathrm{~km} / \mathrm{h}$. The increase of $\mathrm{CO}_{2}$ emission occurs as the speed drops from 50 to $20 \mathrm{~km} / \mathrm{h}$ and even doubles as speed drops from 20 to $10 \mathrm{~km} / \mathrm{h}$. Figure 5 shows the relationship between $\mathrm{CO}_{2}$ emission and average travel speed. In congested urban areas, measurements that refer to grams per second seem to be much better as the vehicles are often stopped and idling. Moreover, repeated vehicle speed changes often occur in stopand-go traffic conditions, resulting in greater emission rates because fuel consumptions also depend on acceleration.

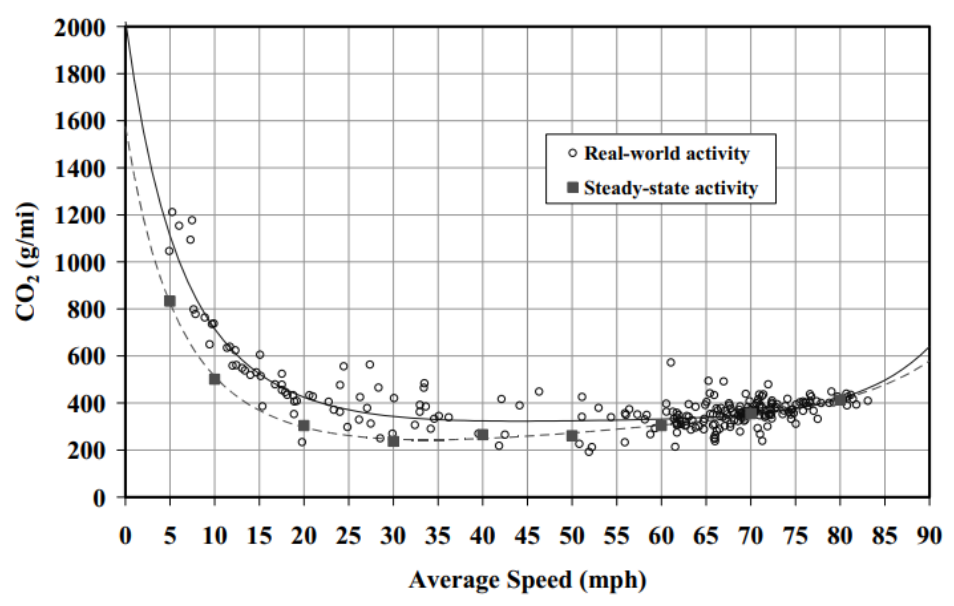

Fig.5. Relationship between $\mathrm{CO}_{2}$ emission and average travel speed [28]

\subsection{Operational performance of signalized intersections}

The relationship between the saturation headway and saturation flow rate is shown following equation:

$$
s_{i}=3600 / h_{i}
$$

Where, $s_{i}$ is saturation flow rate and $h_{i}$ is saturation headway

The effective red time $r$ is calculated as:

$$
R_{i}=\mathrm{C}-g_{i}
$$

Where, $C$ is cycle length and $g_{i}$ is effective green time.

The capacity of lane is defined as follows: 


$$
c_{i}=s_{i} \frac{g_{i}}{C}
$$

Where, ${ }^{g_{i}} / C$ is effective green ratio, $c_{i}$ is capacity of lane.

Interpret measures of capacity sufficiency for intersection performance is shown in Table 2. It is based on the critical volume-to-capacity (v/c) ratio computed for the intersection in Highway Capacity Manual (HCM 2010).

Table 2. Sufficiency of capacity

\begin{tabular}{|c|l|}
\hline Critical v/c ratio & \multicolumn{1}{c|}{ Sufficiency of capacity rating } \\
\hline$<0.85$ & Intersection operate under capacity, and extreme delays are not occurred. \\
\hline $0.85-0.95$ & $\begin{array}{l}\text { Intersection operate near its capacity and higher delays may be expected, } \\
\text { but continuously increasing queues should not occur. }\end{array}$ \\
\hline $0.95-1.00$ & $\begin{array}{l}\text { Unstable traffic flow results in wide range of delays. Improvement of } \\
\text { intersection will be required to avoid extreme delays. }\end{array}$ \\
\hline$>1.00$ & $\begin{array}{l}\text { Demands surpass existing capacity of the intersection. Too many delays } \\
\text { and queuing are expected. }\end{array}$ \\
\hline
\end{tabular}

The concepts of intersection saturation rate and level of service are significant for analysis of the signalized intersections.

Table 3. Level of service for intersections

\begin{tabular}{|c|c|c|}
\hline \multirow{2}{*}{ LOS } & Signalized intersection & unsignalized intersection \\
\cline { 2 - 3 } & \multicolumn{2}{|c|}{ (Seconds) } \\
\hline A & $\leq 10$ & $\leq 10$ \\
\hline B & $>10-20$ & $>10-15$ \\
\hline C & $>20-35$ & $>15-25$ \\
\hline D & $>35-55$ & $>25-35$ \\
\hline E & $>55-80$ & $>35-50$ \\
\hline F & $>80$ & $>50$ \\
\hline
\end{tabular}

To evaluate the capacity and traffic conditions performance analysis at signalized intersections, delay and queue length are the most common indicators. For determining delay and queue length at signalized intersections, capacity and characteristics of system is necessary to know.

Vehicle delays at signalized intersections can be calculated as follows

$$
Q_{d}=\frac{1}{2 C} \cdot \frac{(C-g)^{2}}{\left(1-\frac{v}{s}\right)}
$$

Where, $Q_{d}$ is delay, $v$ is traffic demand, $c$ is capacity demand, $s$ is saturation flow rate, C is cycle time, $g$ is effective green time.

Traffic queues expressed mathematically as follows:

$$
Q_{L}=\frac{T \cdot(v-c)}{N \cdot d_{s}}
$$

Where, $Q_{L}$ is queue length, $T$ is observation time periods, $v$ is observed traffic demand, $c$ is capacity demand, $N$ is number of lanes and $d_{s}$ is traffic density. 


\section{Results and discussion}

In this section, we first analyze the traffic emissions based on traffic data, such as vehicle count and composition. Then we analyze emissions in PTV vissim software. Two intersection alternatives were proposed for the calculation of traffic emissions and operational performance. The first alternative is the existing signalized intersection, fourlane roundabouts. The second alternative is signalized intersection with three through lanes in each through movement, left-turn and channelized right-turn lanes on all approaches. Conceptual computer design in PTV vissim model for the alternatives is shown in Figure 6.

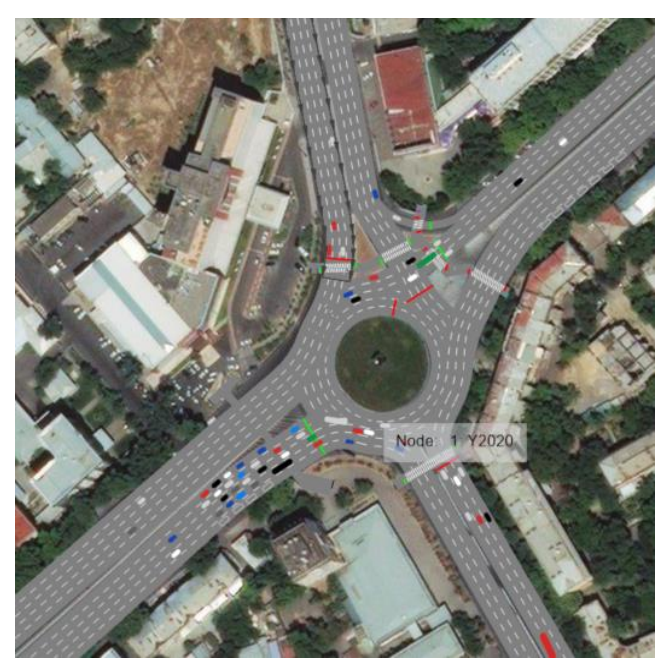

a) Roundabout model

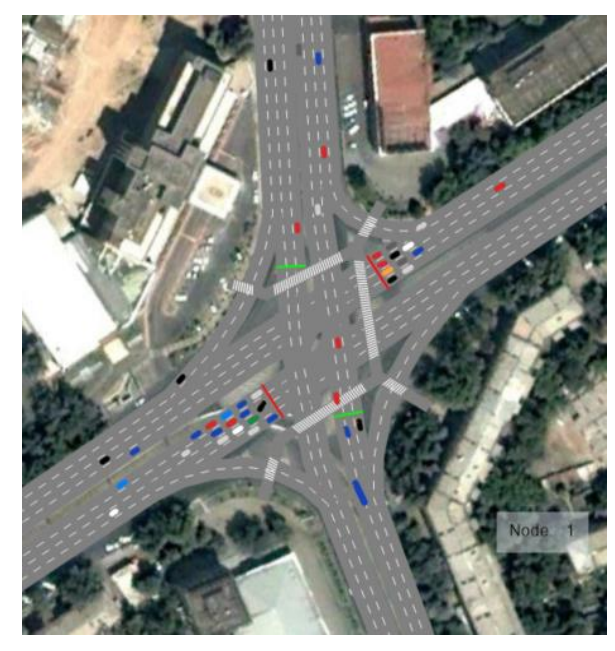

b) Channelized intersection model

Fig. 6. PTV vissim model

Figure 7 illustrates the typical traffic light phasing and movements at the existing fourleg intersection for the roundabout.
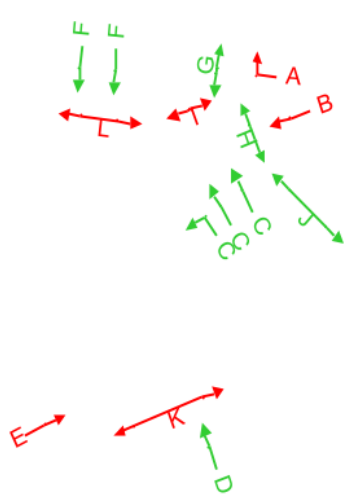

1- Phase
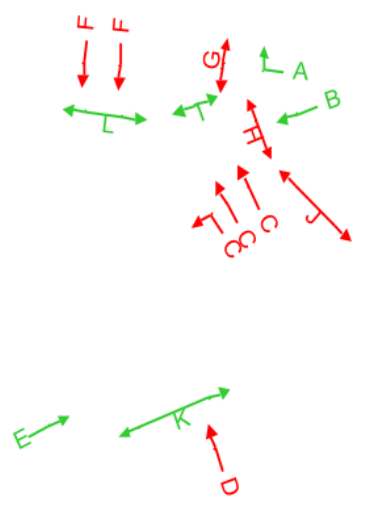

2- Phase

Fig.7. Typical movements at a four-leg intersection 


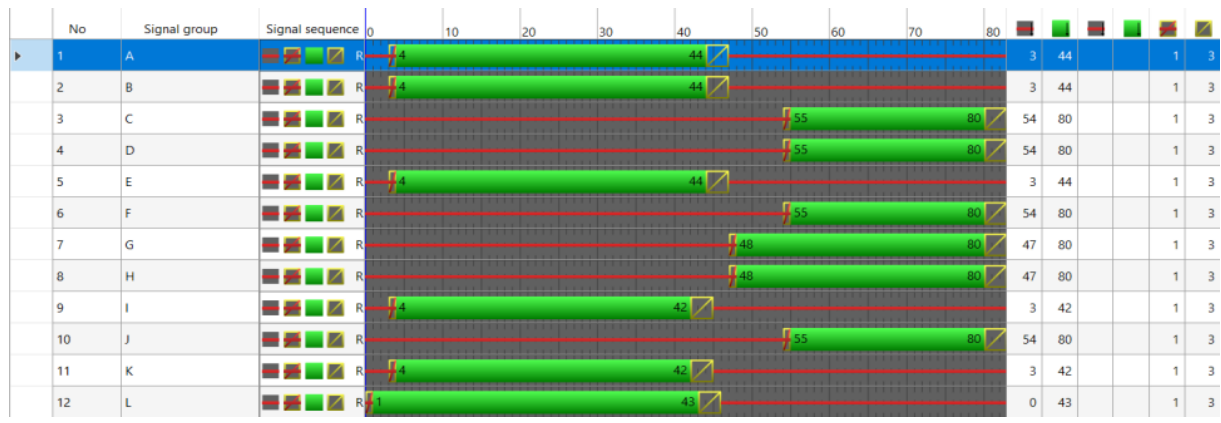

Fig.8. Signal timing plans hour for roundabout for am peak

The duration of the green interval for existing conditions is included in the program as follows (Figure 8). The calculation was performed to analyze hourly traffic data of the intersection in a computer model. Separate analysis and evaluation are required in cases where traffic flows can vary significantly during rush hour in the morning and afternoon.

Table 4. Comparative results for different intersection types

\begin{tabular}{|l|l|l|l|}
\hline$\#$ & \multicolumn{1}{|c|}{ Parameters } & $\begin{array}{l}\text { Alternative 1 } \\
\text { (Roundabout) }\end{array}$ & $\begin{array}{l}\text { Alternative 2 } \\
\text { (Channelized intersection) }\end{array}$ \\
\hline 1 & Level of service (LOS) & C & C \\
\hline 2 & Average vehicle delay (sec) & 30.38 & 23.3 \\
\hline 3 & Average queue length (m) & 37.66 & 8.88 \\
\hline 4 & Maximal queue length (m) & 162.31 & 118.6 \\
\hline 5 & Number of vehicle stops & 1.05 & 0.95 \\
\hline 6 & Number of vehicles & 5494 & 5083 \\
\hline 7 & Carbon monoxide - CO (grams) & 9458.5 & 7791.01 \\
\hline 8 & Nitrogen oxides - NOx (grams) & 1840.19 & 1515.85 \\
\hline 9 & $\begin{array}{l}\text { Volatile organic compounds -VOC } \\
\text { (grams) }\end{array}$ & 2191.99 & 1805.64 \\
\hline 10 & Fuel consumption (liters) & 512.2 & 421.92 \\
\hline
\end{tabular}

The simulation results of the PTV vissim model is shown in Table 4 for both intersection types. The hourly traffic volume of the intersection is 5484 vehicles by manually counting (Figure 4). Simulated results of the computer model show 5494 vehicles. The Difference is $0.2 \%$. The average travel speed of traffic is given in Figure 9. Traffic emissions concentration is plotted in Figure 10 and Figure 11. The maximum length of the queue is $162.31 \mathrm{~m}$, and the average delay of vehicles is $30.38 \mathrm{sec}$. The level of service (LOS) is level C. At the same number of values, when the typical intersection is simulated for alternative $\# 2$, it is found that the level of service is $\mathrm{C}$, and the maximum length of the queue is $118.6 \mathrm{~m}$, the average delay of vehicles is $23.3 \mathrm{sec}$ and the number of vehicles is 5083 respectively.

As shown in Table 4, both alternatives will have good traffic performance within the design type, and they have similar delays. 


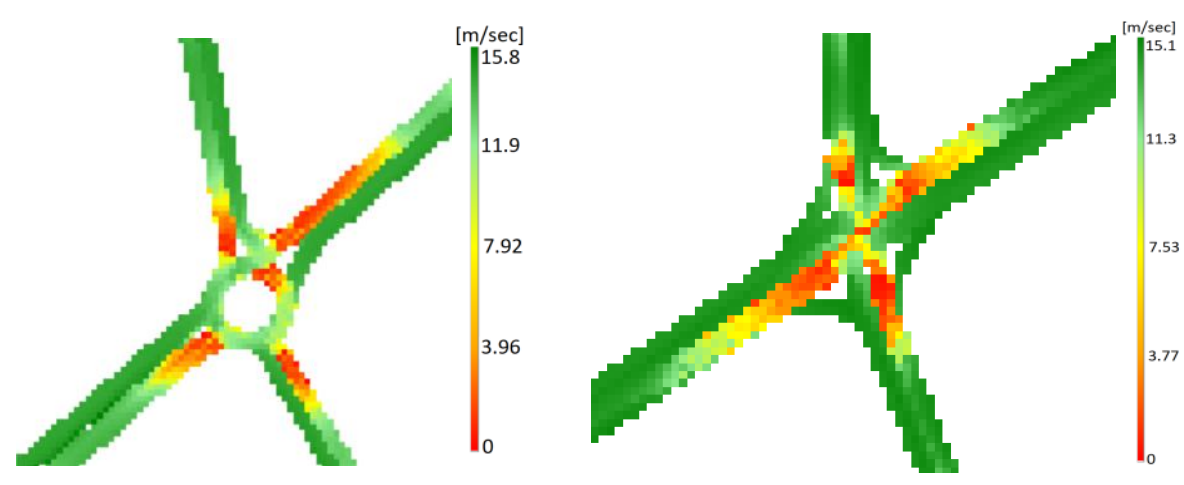

Fig.9. Traffic speed at intersection
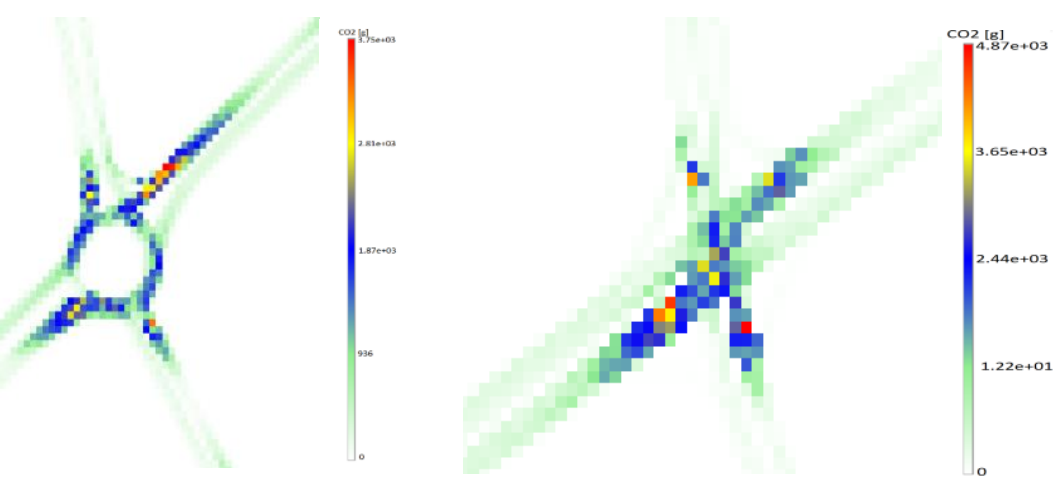

Fig. 10. Distribution of NOx emissions during peak hours at intersection
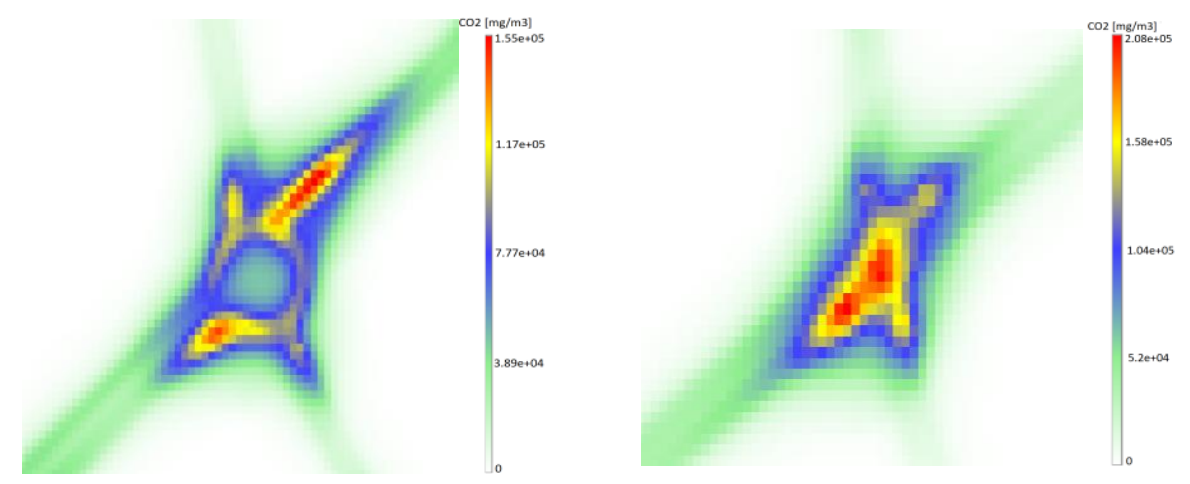

Fig.11. Distribution of $\mathrm{CO} 2$ emissions during peak hours at intersection

The main advantage of the roundabout at this location is the reduction of the expected conflict. With similar traffic performance, the roundabout has better than during the analysis. After 5 years, traffic estimation and analysis showed that the LOS for a typical intersection deteriorated quickly, while the LOS for roundabout deteriorated slowly. If the planning intersection is much longer than 5 years, $4+4$ lanes typical intersection may not meet traffic requirements. In general, the roundabout will have a higher capacity than the typical intersection, while the roundabout has more safety benefit because the signalized intersections have more flexibility to adjust timing. 
Table 5. Comparative results

\begin{tabular}{|c|c|c|c|}
\hline \multirow{2}{*}{ Status } & \multirow{2}{*}{ Parameters } & \multicolumn{2}{|l|}{ Years } \\
\hline & & 2020 & 2025 \\
\hline Alternative\#1 & \multirow{2}{*}{ LOS } & $\mathrm{C}$ & $\mathrm{E}$ \\
\hline Alternative\#2 & & $\mathrm{C}$ & $\mathrm{F}$ \\
\hline Alternative\#1 & \multirow{2}{*}{$\begin{array}{l}\text { Average queue } \\
\text { length }(\mathrm{m})\end{array}$} & 37.66 & 119.69 \\
\hline Alternative $\# 2$ & & 8.88 & 67.59 \\
\hline Alternative\#1 & \multirow{2}{*}{$\begin{array}{l}\text { Maximal queue } \\
\text { length }(\mathrm{m})\end{array}$} & 162.31 & 231.45 \\
\hline Alternative\#2 & & 118.6 & 234.39 \\
\hline Alternative\#1 & \multirow{2}{*}{ Delays (sec) } & 30.38 & 71.02 \\
\hline Alternative\#2 & & 23.3 & 101.52 \\
\hline Alternative\#1 & \multirow{2}{*}{ Number of Stops } & 1.05 & 2.74 \\
\hline Alternative\#2 & & 0.95 & 4.54 \\
\hline Alternative\#1 & \multirow{2}{*}{ Number of vehicles } & 5494 & 6922 \\
\hline Alternative\#2 & & 5083 & 5857 \\
\hline Alternative\#1 & \multirow{2}{*}{$\begin{array}{l}\text { Fuel consumptions } \\
\text { (liters) }\end{array}$} & 512.2 & 1156.68 \\
\hline Alternative\#2 & & 421.92 & 1557.72 \\
\hline Alternative\#1 & \multirow{2}{*}{$\mathrm{CO}$ (grams) } & 9458.5 & 21358.75 \\
\hline Alternative\#2 & & 7791.01 & 28764.34 \\
\hline Alternative\#1 & \multirow{2}{*}{ NOx (grams) } & 1840.19 & 4155.64 \\
\hline Alternative\#2 & & 1515.85 & 5596.5 \\
\hline Alternative\#1 & \multirow{2}{*}{ VOC (grams) } & 2191.99 & 4950.1 \\
\hline Alternative\#2 & & 1805.64 & 6666.41 \\
\hline
\end{tabular}

\section{Conclusions}

In conclusion, we can emphasize the following. An organization or enterprise implementing a road crossing project in any geographical area is required to act with caution concerning their operational and design aspects, public exposures, user needs, and public acceptance. All complicating factors should be addressed using a model before selecting the type of intersection as the optimal option for the intersection.

This study evaluates operational performance and calculation traffic emission of the studied signalized intersection using microscopic traffic simulation. The recorded video camera counted traffic demand data. Signal timing parameters were manually collected and processed using the PTV vissim program. The studied intersection was modelled in VISSIM microscopic simulation. Results showed that signal timings and phasing schemes are associated with the operational performance and emission level of signalized intersection by reducing or increasing the potential traffic flow.

Findings from this study can be expanded to compare the operational performance of signalized roundabouts with signalized typical intersections in different signal timings and phasing scheme. While it is expected that there are significant improvements from the traffic operation and emissions, the differences in terms of traffic emission and safety can be further investigated. 


\section{References}

1. T. Le et al, Unexpected air pollution with marked emission reductions during the COVID-19 outbreak in China, Science (80), doi: 10.1126/science.abb7431. (2020)

2. S. Anenberg, J. Miller, D. Henze, and R. Minjares, A global snapshot of the air pollution-related health impacts of transportation sector emissions in 2010 and 2015, Int. Counc. Clean Transp., (2019).

3. J. He, K. Chen, and J. Xu, Urban Air Pollution and Control, in Encyclopedia of Sustainable echnologies, (2017).

4. Y. Wu et al., On-road vehicle emissions and their control in China: A review and outlook," Sci. Total Environ., doi: 10.1016/j.scitotenv.2016.09.040. (2017).

5. C. K. Gately, L. R. Hutyra, S. Peterson, and I. Sue Wing, Urban emissions hotspots: Quantifying vehicle congestion and air pollution using mobile phone GPS data," Environ. Pollut, doi: 10.1016/j.envpol.2017.05.091. (2017)

6. K. Zhang and S. Batterman, Air pollution and health risks due to vehicle traffic, Sci. Total Environ., , doi: 10.1016/j.scitotenv.2013.01.074. (2013)

7. A. Faiz, C. S. Weaver, and M. P. Walsh, Air pollution from motor vehicles: standards and technologies for controlling emissions. (1996).

8. M. A. Figliozzi, The impacts of congestion on time-definitive urban freight distribution networks CO2 emission levels: Results from a case study in Portland, Oregon,” Transp. Res. Part C Emerg. Technol., 2011, doi: 10.1016/j.trc.2010.11.002. (2011).

9. H. S. Chong, Y. Park, S. Kwon, and Y. Hong, Analysis of real driving gaseous emissions from light-duty diesel vehicles, Transp. Res. Part D Transp. Environ., doi: 10.1016/j.trd.2018.09.015. (2018).

10. H. Igliński and M. Babiak, Analysis of the Potential of Autonomous Vehicles in Reducing the Emissions of Greenhouse Gases in Road Transport, doi: 10.1016/j.proeng.2017.06.061. (2017).

11. G. P. Marcilio, J. J. de A. Rangel, C. L. M. de Souza, E. Shimoda, F. F. da Silva, and T. A. Peixoto, Analysis of greenhouse gas emissions in the road freight transportation using simulation, J. Clean. Prod., doi: 10.1016/j.jclepro.2017.09.171. (2018).

12. S. Zhong and M. Bushell, Impact of the built environment on the vehicle emission effects of road pricing policies: A simulation case study, Transp. Res. Part A Policy Pract, doi: 10.1016/j.tra.2017.06.007.(2017)

13. Y. Xing et al, The Characteristics of Greenhouse Gas Emissions from Heavy-Duty Trucks in the Beijing-Tianjin-Hebei (BTH) Region in China, Atmosphere (Basel), doi: 10.3390/atmos7090121. (2016).

14. International Energy Agency, Emission Factor for Greenhouse Gas Inventories, Iea, (2017).

15. N. Kholod et al., A methodology for calculating transport emissions in cities with limited traffic data: Case study of diesel particulates and black carbon emissions in Murmansk, Sci. Total Environ., doi: 10.1016/j.scitotenv.2015.12.151. (2016).

16. K. Hirschmann, M. Zallinger, M. Fellendorf, and S. Hausberger, A new method to calculate emissions with simulated traffic conditions, doi: 10.1109/ITSC.2010.5625030. (2010).

17. S. Nocera, C. Ruiz-Alarcón-Quintero, and F. Cavallaro, Assessing carbon emissions from road transport through traffic flow estimators, Transp. Res. Part C Emerg. Technol, doi: 10.1016/j.trc.2018.07.020. (2018).

18. C. Mensink and G. Cosemans, From traffic flow simulations to pollutant concentrations in street canyons and backyards, Environ. Model. Softw, doi: 10.1016/j.envsoft.2007.06.005. (2008). 
19. K. Zhang, S. Batterman, and F. Dion, Vehicle emissions in congestion, Comparison of work zone, rush hour and free-flow conditions, Atmos. Environ., doi: 10.1016/j.atmosenv.2011.01.030. (2011).

20. K. Ropkins et al, Real-world vehicle exhaust emissions monitoring: review and critical discussion, Critical Reviews in Environmental Science and Technology. doi: 10.1080/10643380701413377.(2009).

21. S. Kumar Pathak, V. Sood, Y. Singh, and S. A. Channiwala, Real world vehicle emissions: Their correlation with driving parameters," Transp. Res. Part D Transp. Environ, doi: 10.1016/j.trd. 2016.02.001. (2016).

22. G. Fontaras, N. G. Zacharof, and B. Ciuffo, Fuel consumption and CO2 emissions from passenger cars in Europe - Laboratory versus real-world emissions, Progress in Energy and Combustion Science, doi: 10.1016/j.pecs.2016.12.004. (2017).

23. R. Jaikumar, S. M. Shiva Nagendra, and R. Sivanandan, Modal analysis of real-time, real world vehicular exhaust emissions under heterogeneous traffic conditions, Transp. Res. Part D Transp. Environ., doi: 10.1016/j.trd.2017.06.015. (2017).

24. R. Jaikumar, S. M. Shiva Nagendra, and R. Sivanandan, Modeling of real time exhaust emissions of passenger cars under heterogeneous traffic conditions, Atmos. Pollut. Res., doi: 10.1016/j.apr.2016.07.011. (2017).

25. K Kutlimuratov and A Mukhitdinov, Impact of stops for bus delays on routes, IOP Conf. Ser.: Earth Environ. Sci. 614 012084, https://doi.org/10.1088/17551315/614/1/012084. (2020).

26. M. C. Bell, Environmental factors in intelligent transport systems, IEE Proc. Intell. Transp. Syst., doi: 10.1049/ip-its:20060017. (2006).

27. K. Małecki, S. Iwan, and K. Kijewska, Influence of Intelligent Transportation Systems on Reduction of the Environmental Negative Impact of Urban Freight Transport Based on Szczecin Example, Procedia - Soc. Behav. Sci., doi: 10.1016/j.sbspro.2014.10.021. (2014).

28. M. Barth and K. Boriboonsomsin, Real-world carbon dioxide impacts of traffic congestion, Transp. Res. Rec., 2008, doi: 10.3141/2058-20.. (2008). 